\title{
Are Herniated Cerebellar Tonsils the Main Culprit of Chiari Malformation Type I Symptoms? The Brainstem Compression Hypothesis seems to be Re-Elucidated and Revised
}

\author{
Mehmet SELCUKI ${ }^{1}$, Mesut METE ${ }^{1}$, Deniz SELCUKI ${ }^{2}$ \\ ${ }^{1}$ Celal Bayar University, School of Medicine, Department of Neurosurgery, Manisa, Turkey \\ ${ }^{2}$ Celal Bayar University, School of Medicine, Department of Neurology, Manisa, Turkey
}

\section{ABSTRACT}

AIM: The Chiari Malformation I (CM I) and the tethered cord syndrome (TCS) are both congenital abnormalities whose mechanisms are still not fully understood. The association of CM I and TCS has been reported only a few times previously.

MATERIAL and METHODS: This retrospective study included 7 patients who were diagnosed with CM I and TCS, managed by cutting of the filum terminale.

RESULTS: The mean follow-up period was 21 months and 28 days. Although all patients underwent an untethering surgical procedure by cutting the filum terminale only, all patients reported significant early postsurgical resolution of CM I symptoms and symptoms related to TCS as well.

CONCLUSION: Patients with symptomatic CM I, even if lumbar MRI is normal and the patient asymptomatic for TCS, may have tethered spinal cord at the same time. It seems it would be worthwhile to investigate CM I patients for occult TCS with spinal somatosensory evoked potentials.

KEYWORDS: Chiari I Malformation, Tethered Cord Syndrome, Untethering

\section{INTRODUCTION}

$\mathrm{T}$ The Chiari malformation I (CM I) is a disorder that has been defined as downward herniation of the cerebellar tonsils at least $5 \mathrm{~mm}$ or greater through the foramen magnum which is a leading cause of syringomyelia and occurs in association with osseous abnormalities at the craniovertebral junction (8). In CM I, posterior fossa decompression, with or without duraplasty, is preferable helpful procedures in symptomatic patients although its mechanism is still unclear.

Tethered Cord Syndrome (TCS) is characterized by clinical signs and symptoms such as back/leg pain, orthopedic abnormalities (including scoliosis and foot deformities) and neurological deficits including motor weakness, sensory disturbances and urinary or stool incontinence (2). The demonstration of TCS is based on the magnetic resonance imaging (MRI) findings such as thick filum terminale ( $>2$ $\mathrm{mm}$ diameter), a low-positioned conus medullaris, posterior displacement of the conus medullaris and filum terminale, and a wide lumbar and sacral subarachnoid space (18). However, if there is no anatomical evidence of low-lying conus on lumbar MRI and the filum terminale has normal thickness, it is difficult to diagnose tethered spinal cord. In such cases, after a somatosensory evoked potentials study, sectioning of filum terminale in case of a tethered cord diagnosis often helps resolve the symptoms but the indications for cutting the filum in this context are still controversial $(6,14)$. 
Seven cases reported in this paper were diagnosed as CM I at first. However, the additional complaints of these cases that are related to tethered cord directed us to discuss whether these symptoms may be related to tethered spinal cord instead of CM I. Spinal somatosensory evoked potential (SSEP) study performed on these cases and conduction delay or blockade was considered a positive clue for tethered spinal cord, and we have performed surgical untethering procedure on these cases before an approach for herniated cerebellar tonsils as suggested by Milhorat et al.(7).

The association of CM I and TCS, in which pathophysiological mechanisms are not clearly understood, has been reported only a few times previously $(2,7,10,16)$. In this article, the authors reported 7 patients with association of CM I and TCS, who were managed by cutting the filum terminale only with good outcomes.

\section{MATERIAL and METHODS}

This retrospective study includes 7 patients who were diagnosed with CM I and TCS and managed by cutting of the filum terminale in the Neurosurgery Department of Celal Bayar University, School of Medicine. There were 2 male and 5 female patients. The detailed characteristics of the patients are shown in Table I. Epidemiological data, clinical charts, imaging and surgical observation and follow-up data were reviewed for each patient. Each patient underwent detailed neurological and radiological examination to determine both $\mathrm{CM} \mathrm{I}$ and TCS. Radiological consideration for the diagnosis of CM I was made based on the following criteria: downward herniation of the cerebellar tonsils through the foramen magnum with or without syringomyelia. A clinical consideration for the diagnosis of TCS was made based on the following criteria: back and/or leg pain, lower extremity numbness, neurological deficits and urinary/stool incontinence and scoliosis. Radiological diagnosis was made based on the following criteria: conus medullaris below the $\mathrm{L} 2$ vertebral body level, thickened or fatty filum. Patients suspected for TCS based on the clinical findings, who had normal level conus medullaris with normal thickness, were evaluated by SSEP, which we reported previously $(11,12)$. In addition, patients, who were symptomatic for CM I and asymptomatic for TCS, were evaluated by SSEP in order to diagnose occult TCS.

\section{Surgery}

Patients underwent a standard L5 total laminectomy and intradural untethering operation was performed under the surgical microscope by cutting the filum terminale. Neuromonitoring was performed during surgery.

\section{RESULTS}

The mean follow-up period was 21 months and 28 days. All patients reported significant early postsurgical resolution of CM I symptoms as well as symptoms related to TCS. There were no surgical complications such as cerebrospinal fluid (CSF) leakage or neurological deficits. Patients were mobilized at postoperative $2^{\text {nd }}$ day and discharged on postoperative $5^{\text {th }}$ day. During the postoperative period, MRI demonstrated disappearance of syringomyelia in one patient and decrease of cavity in one patient. We did not notice upward replacement of the cerebellar tonsils radiographically. However, during the postoperative period (ranging from 6 months to 33 months) all patients had significant and/or complete improvement as far as the complaints from Chiari type I malformation were concerned.

\section{Illustrative Cases}

Case-3: A 44-year-old male patient presented with cervical and back pain. In his history, cervical pain had started 2 years earlier and back pain was added 8 months ago. He was referred to us for CM I surgery. His neurological examination was normal. Because of his back pain, we investigated him by $\mathrm{MRI}$ and lumbar MRI demonstrated fatty filum terminale. SSEP revealed blockade both lumbar and thoracic evoked potential waves. During surgery, L5 total laminectomy was performed. Under the surgical microscope, the dura mater was opened and the fatty filum terminale was cut. Complete improvement was noted at postoperative 33 months, and cervical MRI detected disappearance of cervical syringomyelia (Figure 1AD)

Case-4: A 51-year-old female patient was referred to our medical facility for her headaches, which were thought to be related to cerebellar tonsil herniation. Cerebellar tonsil herniation was found on her MRI investigation, which was performed for her headache episodes. She was referred to us for CM I because of herniated cerebellar tonsils. In her history, she also had leg pain. She had used medication for a long time, but no improvement was obtained. Her neurological examination was normal. Because of her leg pain, lumbar MRI was planned. Lumbar MRI demonstrated thick filum terminale and SSEP revealed blockade in cervical, lumbar and thoracic evoked waves. During surgery, L5 total laminectomy was performed. Under the surgical microscope, the dura mater was opened and the thick filum terminale was cut. Complete improvement was noted at postoperative 32 months, and cervical MRI detected decrease in the cervical cavity (Figure 2A-D).

\section{- DISCUSSION}

Previously, etiopathogenesis of CM has been explained with a caudal fixation of the spinal cord in utero which prevents the normal ascent of neuroaxis during growth and development, resulting in downward displacement of the cerebellum and brain stem through the foramen magnum $(5,7)$. Now this theory is called the "old theory of cerebellar tonsils herniation". It has been understood that dentate ligaments prevent traction effect of the fixed spinal cord to be conducted up to the brain stem, which in turn causes cerebellar tonsils herniation. Also, it has been reported that a tight filum terminale may cause spinal cord compression over an angulated spine as well as cord traction, pulling the hindbrain into the foramen magnum $(1,10)$. However, validity of this mechanical traction hypothesis has been discussed seriously and has not been accepted for 2 reasons. First, it has shown that, the tethered cord syndrome may also occur in patients who have the conus medullaris 
in the normal position (13) and the second, cadaveric and experimental models does not support this hypothesis $(3,15)$. In a study with fresh cadavers, Tubbs et al. reported that caudal tension on the conus medullaris caused less than 1 $\mathrm{mm}$ downward movement of the medulla and upper cervical cord without cerebellar tonsils displacement which means caudal fixation of the spinal cord is implausible for CM I pathophysiology (15).

Recently, CM I associated with TCS, characterized by a low lying conus medullaris, as well as a normal level conus medullaris, has been reported by a few publications $(2,7,10,16)$ and this togetherness has attracted great interest and led to speculations. Royo-Salvador et al. reported an association between TCS, syringomyelia, scoliosis and CM I in 20 patients and suggested sectioning the filum terminale as the surgical treatment of these conditions. The authors advised that the improvement of symptoms with syringomyelia and CM I after section of the filum terminale might depend on the relief on traction and compression of the pericavitary medullary tissue and relief on tension over the cervical cord. The authors also noted that the syrinx was decreased in two cases and unchanged in one case. In addition, improvement of tonsillar herniation was reported (10). In a large clinical series, Milhorat et al. reported 318 detethering filum terminale patients selected from 2987 patients with CM I. The authors determined clinical and radiological improvement. Namely, clinical improvement was determined in $85 \%$ of the patients and radiological improvement such as syringomyelia and scoliosis were detected in 55 and $33 \%$ of the patients respectively (7). In present study, 3 of 7 patients had a syrinx and 1 of 7 had a cavity. Postoperative period MRI demonstrated disappearance of syrinx in one case (Figure 1, Case-3), decrease in cavity in one case (Figure 2, Case-4) and the others were unchanged. We did not determine a decrease in tonsillar herniation on $\mathrm{MRI}$ in the postoperative period. The symptoms of all patients significantly recovered after surgery. Although we cannot fully explain the pathophysiology of this improvement, we believe this clinical improvement might be due to restoring of the CSF circulation rather than resolving of the traction effect after detethering of the filum terminale.

In the assessment of patients, we rely on the efficiency of SSEP besides radiology and clinical findings. While the usefulness of SSEP in CM I is still debated, it can be used in order to provide functional balance and to answer specific questions in TCS. Vidmer et al. previously reported that SSEP as a noninvasive neurological examination is able to provide useful information in asymptomatic or clinically stable patients in TCS and CM I (17). It is known that the degree of tethering in TCS is not enough to cause symptoms alone, but repetitive movements increase the tension on the spinal cord and eventually lead to appearance of symptoms $(4,9)$. This means that the intensity of the tethering effect determines the timing
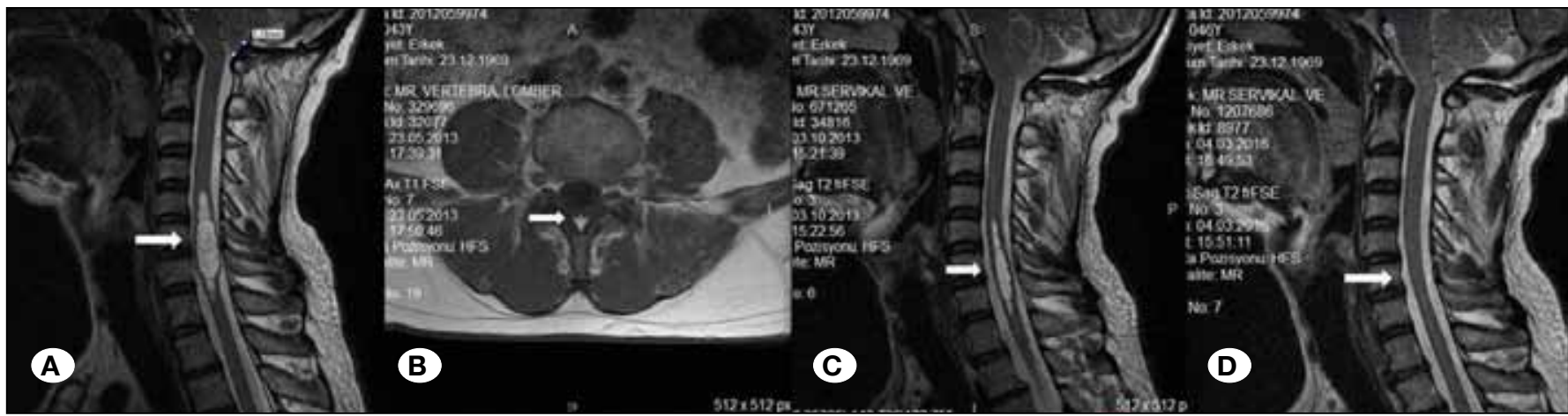

Figure 1: A) Sagittal cervical MRI (white arrow) demonstrated CM I with syringomyelia. B) Axial lumbar MRI demonstrated (white arrow) fatty filum terminale. On postoperative $5^{\text {th }}$ and $33^{\text {th }}$ months sagittal cervical MRls detected a decrease in and disappearance of the syringomyelia in (C) and (D) respectively.

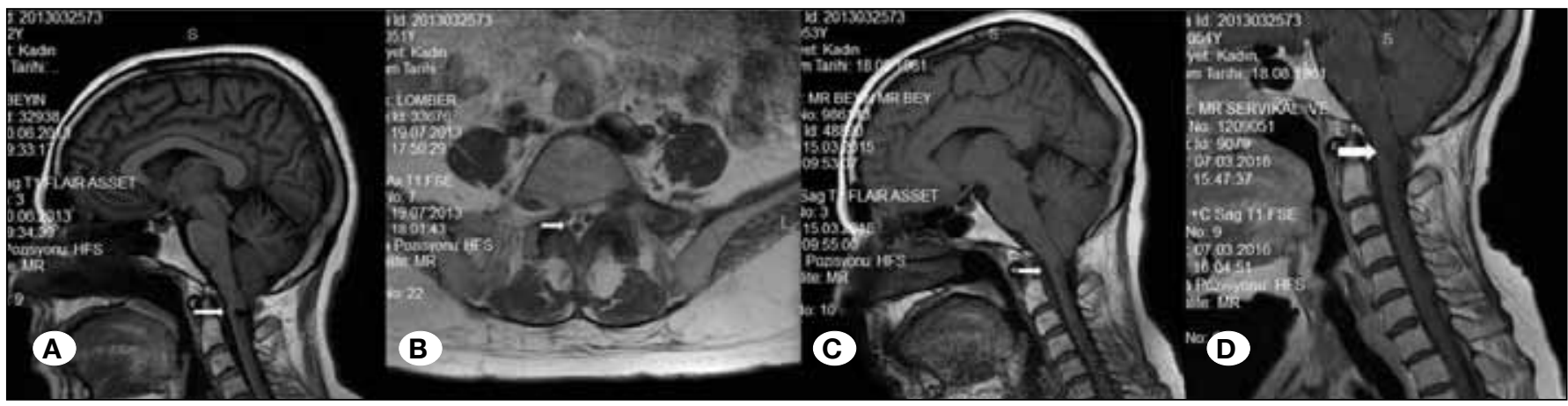

Figure 2: A) Sagittal cervical MRI demonstrated (white arrow) CM I with cervical cavity. B) Axial lumbar MRI demonstrated thick filum terminale (white arrow). On postoperative $20^{\text {th }}$ and $32^{\text {th }}$ months a decrease in cervical cavity was observed in (C) and (D) respectively. 
Table I: The Detailed Characteristics of the Patients

\begin{tabular}{|c|c|c|c|c|c|}
\hline Case & $\begin{array}{l}\text { Sex, age } \\
\text { (years) }\end{array}$ & Diagnosis & Complaints & Observation (MRI) & $\begin{array}{l}\text { Outcome Follow-up } \\
\text { time }\end{array}$ \\
\hline 1 & $19, \mathrm{~F}$ & Chiari I+Syrinx+NLCM+NTFT & $\begin{array}{l}\text { Headache, Leg pain, leg } \\
\text { Numbness, Scoliosis }\end{array}$ & $\begin{array}{c}\text { No change in syrinx and } \\
\text { tonsil herniation }\end{array}$ & $\begin{array}{l}\text { 75\% Improvement } \\
17 \text { months }\end{array}$ \\
\hline 2 & $38, F$ & Chiari I+ NLCM+NTFT & $\begin{array}{l}\text { Suboccipital headache, } \\
\text { Arm numbness, back } \\
\text { and leg pain }\end{array}$ & $\begin{array}{l}\text { No change in tonsil } \\
\text { herniation }\end{array}$ & $\begin{array}{l}70 \% \text { Improvement } \\
24 \text { months }\end{array}$ \\
\hline 3 & $44, \mathrm{M}$ & Chiari I+Syrinx+ NLCM+FFT & $\begin{array}{l}\text { Cervical pain and back } \\
\text { pain }\end{array}$ & $\begin{array}{c}\text { Disappear in syrinx. } \\
\text { No change in tonsil } \\
\text { herniation }\end{array}$ & $\begin{array}{l}\text { Complete Improvement } \\
33 \text { months }\end{array}$ \\
\hline 4 & $51, \mathrm{~F}$ & Chiari I+ Syrinx+NLCM+TFT & Cervical and leg pain & $\begin{array}{c}\text { Decrease in cavity. } \\
\text { No change in tonsil } \\
\text { herniation }\end{array}$ & $\begin{array}{l}\text { Complete Improvement } \\
32 \text { months }\end{array}$ \\
\hline 6 & $33, \mathrm{M}$ & Chiari I+ Syrinx+ NLCM+NTFT & $\begin{array}{l}\text { Cervical and arm pain, } \\
\text { weakness in both arm, } \\
\text { Scoliosis }\end{array}$ & $\begin{array}{c}\text { No change in syrinx and } \\
\text { tonsil herniation }\end{array}$ & $\begin{array}{l}\text { 60\% Improvement } \\
12 \text { months }\end{array}$ \\
\hline 7 & $14, F$ & Chiari I+ NLCM+NTFT & $\begin{array}{c}\text { Hand numbness, } \\
\text { headache and cervical } \\
\text { pain }\end{array}$ & $\begin{array}{c}\text { No change in tonsil } \\
\text { herniation }\end{array}$ & $\begin{array}{l}70 \% \text { Improvement } \\
25 \text { months }\end{array}$ \\
\hline
\end{tabular}

NLCM: Normal level conus medullaris, TFFT: Thick fatty filum terminale, TFT: Thick filum terminale, NTFT: Normal thickness filum terminale.

of the onset of the symptoms. So, patients with symptomatic $\mathrm{CM}$ I could have asymptomatic spinal cord tethering. At this point, the question 'Can we use SSEP to detect occult TCS in symptomatic CM I patients who were asymptomatic for TCS?' comes to mind. In the present study, 2 of 7 patients (Case- 5 and Case-7) had CM I symptoms such as headache, cervical pain and arm numbness (Table I). However these patients had silent TCS, and SSEP revealed thoracic and lumbar blockade of conduction in both patients. We planned surgery for TCS, and tethered filum terminale with normal thickness was observed during surgery. During the postoperative period, both patients reported significant improvement in their complaints. This effect might be due to re-organization of CSF flow after relieving the tethered filum terminale or the spinal cord in other words.

\section{CONCLUSION}

Patients with symptomatic CM I (even lumbar MRI is normal and the patient is asymptomatic for TCS) may have tethered spinal cord at the same time. It seems it is worthwhile to investigate CM I patients for occult TCS with SSEP. If SSEP reveals conduction delay or blockade, an untethering procedure could be preferred before more complex CM I surgery.

\section{REFERENCES}

1. Garceau GJ: The filum terminale syndrome (the cord-traction syndrome). J Bone Joint Surg Am 35-A(3):711-716, 1953

2. Glenn C, Cheema AA, Safavi-Abbasi S, Gross NL, Martin MD, Mapstone TB: Spinal cord detethering in children with tethered cord syndrome and Chiari type 1 malformations. J Clin Neurosci 22(11):1749-1752, 2015

3. Goldstein F, Kepes JJ: The role of traction in the development of the Arnold-Chiari malformation. An experimental study. $J$ Neuropathol Exp Neurol 25(4):654-666, 1966

4. Hertzler DA 2nd, De Powell JJ, Stevenson CB, Mangano FT: Tethered cord syndrome: A review of the literature from embryology to adult presentation. Neurosurg Focus 29(1):E1, 2010

5. Lichtenstein BW: Distant neuroanatomic complications of spina bifida (spinal dysraphism). Hydrocephalus, ArnoldChiari deformity, stenosis of the aqueduct of Sylvius, etc.; pathogenesis and pathology. Arch Neurol Psychiat 47:195214, 1940

6. Massimi L, Peraio S, Peppucci E, Tamburrini G, Di Rocco C: Section of the filum terminale: Is it worthwhile in Chiari type I malformation? Neurol Sci 32 Suppl 3:S349-351, 2011

7. Milhorat $\mathrm{TH}$, Bolognese PA, Nishikawa M, Francomano CA, McDonnell NB, Roonprapunt C, Kula RW: Association of Chiari malformation type I and tethered cord syndrome: Preliminary results of sectioning filum terminale. Surg Neurol 72(1):20-35, 2009 
8. Milhorat TH, Chou MW, Trinidad EM, Kula RW, Mandell M, Wolpert C, Speer MC: Chiari I malformation redefined: Clinical and radiographic findings for 364 symptomatic patients. Neurosurgery 44(5):1005-1017, 1999

9. Romagna A, Suchorska B, Schwartz C, Tonn JC, Zausinger S: Detethering of a congenital tethered cord in adult patients: An outcome analysis. Acta Neurochir (Wien) 155(5):793-800, 2013

10. Royo-Salvador MB, Solé-Llenas J, Doménech JM, GonzálezAdrio R: Results of the section of the filum terminale in 20 patients with syringomyelia, scoliosis and Chiari malformation. Acta Neurochir (Wien) 147(5):515-523, 2005

11. Selçuki $M$, Coşkun K: Management of tight filum terminale syndrome with special emphasis on normal level conus medullaris (NLCM). Surg Neurol 50(4):318-322, 1998

12. Selcuki M, Mete M, Barutcuoglu M, Duransoy YK, Umur AS, Selcuki D: Tethered cord syndrome in adults: Experience of 56 patients. Turk Neurosurg 25(6):922-929, 2015
13. Selcuki M, Vatansever S, Inan S, Erdemli E, Bagdatoglu C, Polat $A$ : Is a filum terminale with a normal appearance really normal? Childs Nerv Syst 19(1):3-10, 2003

14. Steinbok P, MacNeily AE: Section of the terminal filum for occult tethered cord syndrome: Toward a scientific answer. Neurosurg Focus 23(2):E5, 2007

15. Tubbs RS, Loukas M, Shoja MM, Oakes WJ: Observations at the craniocervical junction with simultaneous caudal traction of the spinal cord. Childs Nerv Syst 23(4):367-369, 2007

16. Valentini LG, Selvaggio G, Visintini S, Erbetta A, Scaioli V, Solero CL: Tethered cord: Natural history, surgical outcome and risk for Chiari malformation 1 (CM1): A review of 110 detethering. Neurol Sci 32 Suppl 3:S353-356, 2011

17. Vidmer S, Sergio C, Veronica S, Flavia T, Silvia E, Sara B, Valentini LG, Daria R, Solero CL: The neurophysiological balance in Chiari type 1 malformation (CM1), tethered cord and related syndromes. Neurol Sci 32 Suppl 3:S311-316, 2011

18. Yamada S, Lonser RR: Adult tethered cord syndrome. J Spinal Disord 13(4):319-323, 2000 